\title{
Effect of planetary waves on cooling the upper mesosphere and lower thermosphere by the $\mathrm{CO}_{2} 15-\mu \mathrm{m}$ emission
}

\author{
G. M. Shved, V. P. Ogibalov, and A. I. Pogoreltsev \\ Dept. of Atmosph. Phys., Inst. of Phys., St. Petersburg State Univ., St. Petersburg-Petrodvorets 198504, Russia
}

Received: 22 December 2003 - Revised: 17 June 2004 - Accepted: 24 June 2004 - Published: 3 November 2004

\begin{abstract}
The steady-state 2-D linearized model of globalscale waves, calibrated according to available observations, is used to evaluate planetary-wave perturbations of temperature from the surface up to the height of about $165 \mathrm{~km}$. The maximum order of perturbation amplitudes in the upper mesosphere and lower thermosphere is found to be $15 \mathrm{~K}$ for the ultra-fast Kelvin wave (UFKW) of the 3.5-day period, $8 \mathrm{~K}$ for the 10 -day wave, $5 \mathrm{~K}$ for the 2 - and 16 -day waves, and $2 \mathrm{~K}$ for the 5-day wave. The wave-caused variation in heat influx in the $\mathrm{CO}_{2} 15-\mu \mathrm{m}$ band, averaged over the wave period, depends on both the amplitude of temperature and temperature profile in the atmosphere unperturbed by the wave. An additional increase in radiative cooling is the prevailing effect of planetary waves in the upper mesosphere and lower thermosphere. The UFKW results in an increasing cooling rate up to $\sim 0.1$ of the cooling rate in the unperturbed atmosphere. The tangible contributions of the 2-, 10-, and 16-day waves are questionable. The contribution of the 5-day wave is negligible.
\end{abstract}

Key words. Meteorology and atmospheric dynamics (waves and tides; radiative processes)

\section{Introduction}

The main mechanism for the cooling of the atmosphere up to the heights of $110-120 \mathrm{~km}$ is infrared radiative cooling (e.g. Roble, 1995). In the upper mesosphere/lower thermosphere (UMLT) region between $\sim 70$ and $120 \mathrm{~km}$ the $\mathrm{CO}_{2} 15-\mu \mathrm{m}$ emission dominates in infrared cooling (e.g. Fomichev et al., 1986).

The population of atomic and molecular states, which give the atmospheric infrared emission, is controlled by thermal atomic/molecular collisions, either totally (local thermodynamic equilibrium (LTE) for a state of interest) or partially (non-LTE). The efficiency of collisional excitation increases with atmospheric temperature. As a result the rate of radiative cooling depends on temperature. This dependence

Correspondence to: G. M. Shved

(shved@1mupa.phys.spbu.ru) is very complicated since the radiative influx of heat at an atmospheric level is determined as the difference between absorbed energy of the radiation emitted at other levels and energy emitted at the level considered. Thus, the radiative cooling rate depends in a complicated way on the features of vertical temperature profile in a layer of the atmosphere.

The observations show a strong spatial-temporal variability of temperature profile in the upper and middle atmosphere. Any temperature profile observed can be treated as the superposition of a smoothed climatological profile changing with latitude and season and of a perturbation. The perturbations are caused by waves and eddies. The scales of waves and eddies are extremely varied in time and space. That is why the evaluations of the radiative cooling rate are made as a rule for climatological profiles of temperature (e.g. Dickinson, 1984; Fomichev et al., 1986; Khvorostovskaya et al., 2002).

Ignoring the aforementioned perturbations in temperature results in an error in estimating the radiative cooling rate. For the first time, the effect of temperature perturbations in the UMLT region on this rate was analyzed by Kutepov and Shved (1978), who tested an influence of wave-caused perturbations on cooling by the $\mathrm{CO}_{2} 15-\mu \mathrm{m}$ emission. Later, Fomichev et al. (1986) have shown an additional cooling in the $70-110 \mathrm{~km}$ layer, which is produced due to the effect of the 24- and 12-hour tides and internal gravity waves on the $\mathrm{CO}_{2}$ 15- $\mu \mathrm{m}, \mathrm{O}_{3} 9.6-\mu \mathrm{m}$, and $\mathrm{H}_{2} \mathrm{O}$ rotational emissions.

Here we estimate the effect on UMLT radiative cooling of temperature perturbations caused by planetary waves (atmospheric normal modes and equatorial waves) (e.g. Ahlquist, 1985; Andrews et al., 1987). There are many modes of the planetary waves, which differ in zonal number and the period of the wave. We consider the modes which perturb the middle atmosphere most strongly. The 2-, 5-, 10-, and 16day waves among normal modes and the ultra-fast Kelvin wave (UFKW) among equatorial waves have been therefore selected for analyzing.

The planetary waves considered are not steady phenomena. Their lifetimes are no more than several periods of a wave, and the maximum amplitude during manifestations of a wave varies over a wide range (e.g. Lindzen et al., 1984; 
a)

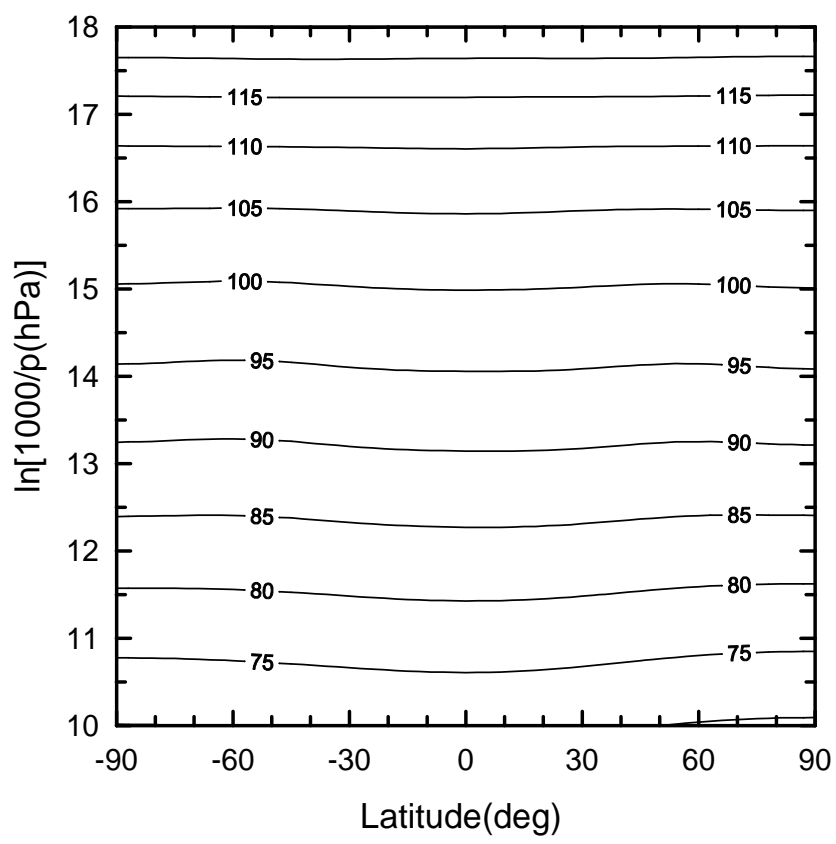

b)

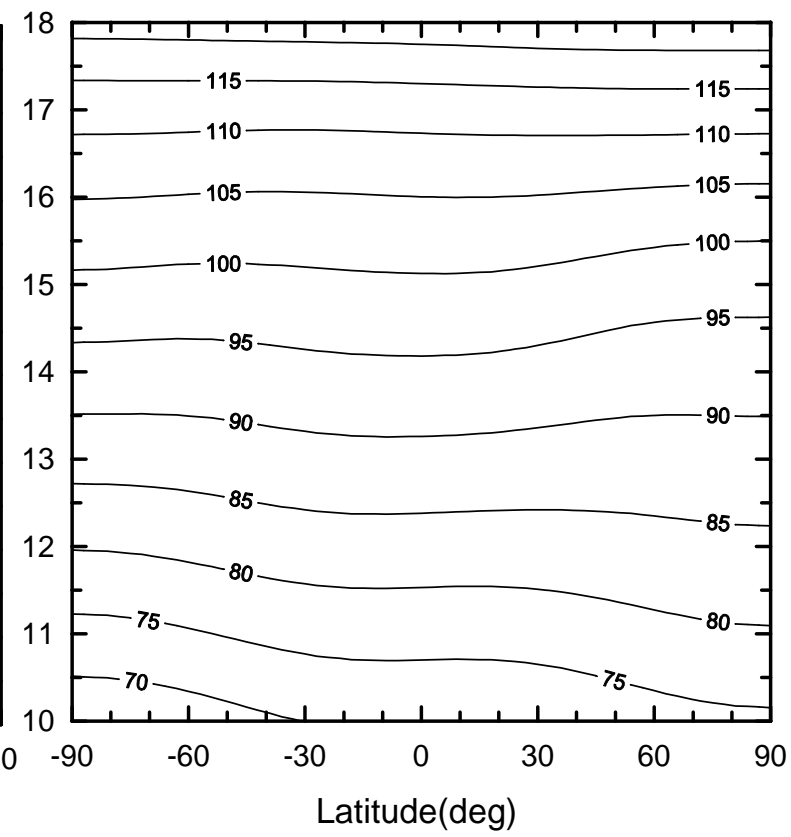

Fig. 1. Relationship between geometrical (in $\mathrm{km}$ ) and log-pressure coordinates in the UMLT region for 16 March (a) and $1 \mathrm{July}$ (b) from the MSISE-90 model (Hedin, 1991).

Ahlquist, 1985). That is why we estimate only a maximum order-of-magnitude for the wave perturbation of radiative cooling rate. Taking into account the only $\mathrm{CO}_{2} 15-\mu \mathrm{m}$ emission is sufficient in our estimating, since this emission dominates in UMLT radiative cooling.

\section{Planetary wave models}

The steady-state 2-D linearized model of global-scale waves, described by Pogoreltsev (1996, 1999, 2001), has been used in this study to simulate wave perturbations of temperature $T$. The model domain extends from the South Pole to the North Pole and from the surface up to the height of about $165 \mathrm{~km}$. The planetary waves modeled are forced by vertical motions at the lower boundary with an arbitrary amplitude of vertical velocity. The solutions obtained are calibrated, i.e. the wave amplitude modeled is multiplied by an appropriate factor to reproduce the amplitudes of planetary-wave perturbations of the temperature, geopotential height, and/or wind, which are observed in the middle atmosphere.

The amplitude of the planetary wave in the UMLT region depends mainly on background zonal wind which varies with season. We have evaluated the wave perturbations of $T$ for two cases which differ considerably in the latitude-height distribution of background wind. We have taken the conditions of 1 July as characteristic for summer/winter. For spring/autumn the conditions of 16 March have been taken, since the zonal wind distribution near this date results in the strongest amplitude in the UMLT region for longer-period planetary waves. The springtime transition in atmospheric circulation of the Northern Hemisphere occurs near this date.
The background temperature and background zonal wind velocity have been taken from the MSISE-90 (Hedin, 1991) and HWM-93 (Hedin et al., 1996) empirical models, respectively. Figure 1 shows the relationship between geometrical height $z$ and dimensionless $\log$-pressure height $\ln (1000 / p)$, where $p$ is the pressure in hPa. Figures 2 and 3 plot the background temperature and wind, respectively.

To reproduce the realistic conditions, the solution was calibrated using the observed amplitudes of the considered planetary waves. The amplitude of temperature perturbations, $\delta T$ for UFKW of the 3.5-day period and zonal wave number $s=1$ found from the UARS Microwave Limb Sounder (MLS) data by Canziani et al. (1994) and revealed by Smith et al. (2002) in the analysis of Cryogenic Infrared Spectrometers and Telescopes for the Atmosphere (CRISTA) data is of $2-3 \mathrm{~K}$ at the height of about $50 \mathrm{~km}$. The amplitudes of the 5-, 10-, and 16-day waves $(s=1)$ were calibrated using the results of analysis of the UK Met Office assimilated data for 1992-2001 (Fedulina et al., 2004). The calculated amplitudes of geopotential height perturbations in the stratosphere are of $60-80 \mathrm{~m}$ for the 5-day wave, and $150-200 \mathrm{~m}$ for 10and 16-day waves. These values correspond to the maximal observed amplitudes of these planetary waves during the time interval considered. The 2-day wave $(s=3)$ has usually been observed in the horizontal wind in the MLT region (Thayparan et al., 1997; Fritts et al., 1999). These observations show an increase in the 2-day wave activity in summer and we will consider only July conditions for this wave. The lower boundary forcing for the 2-day wave was calibrated, to reproduce the observed amplitude of meridional wind perturbation in the summer mesosphere (about of $25 \mathrm{~m} / \mathrm{s}$ ). 
a)

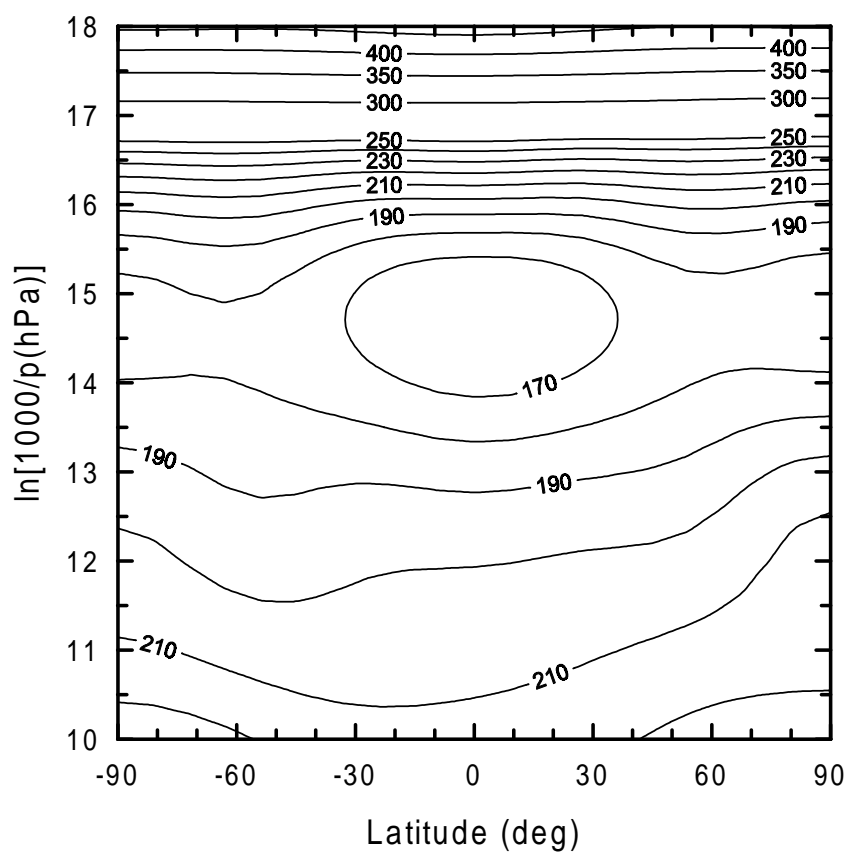

b)

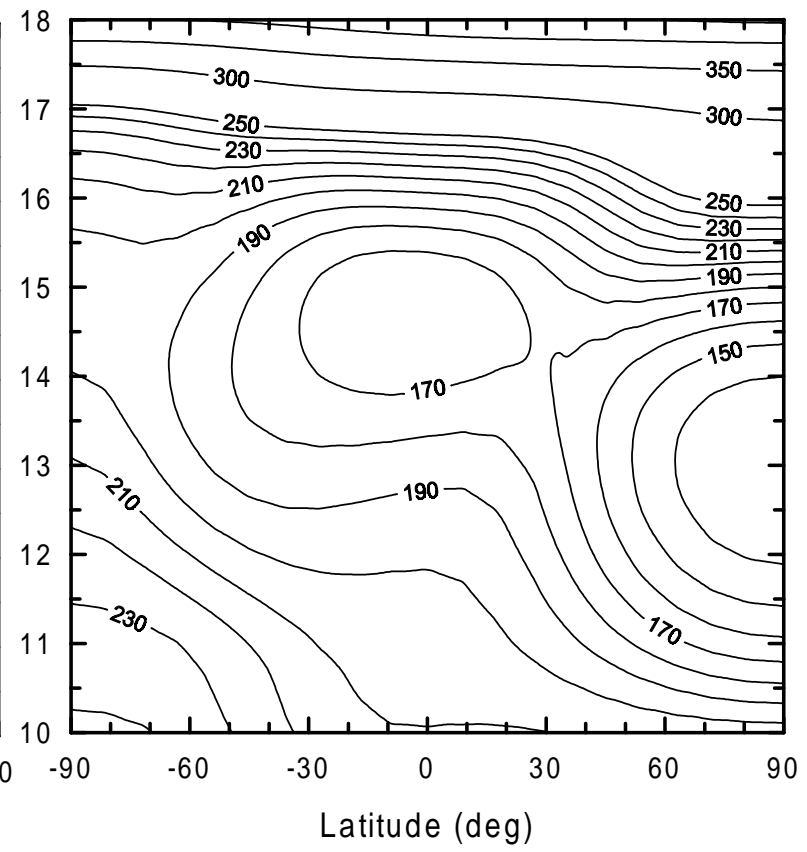

Fig. 2. Latitude-height distributions of background temperature in Kelvin in the UMLT region for 16 March (a) and 1 July (b) from the MSISE-90 model (Hedin, 1991).

a)

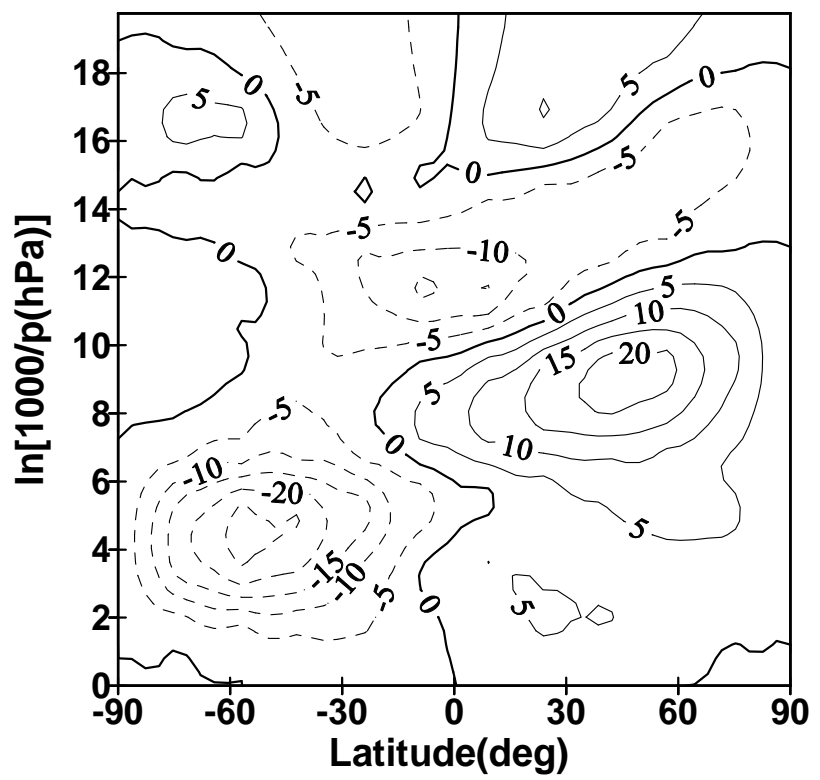

b)

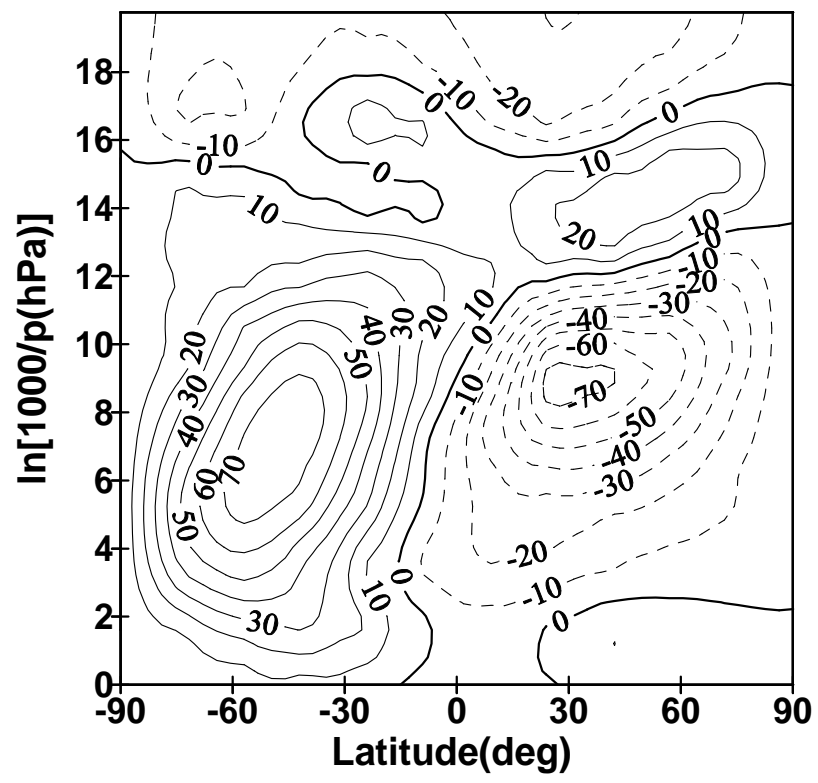

Fig. 3. Latitude-height distributions of velocity of background zonal wind in $\mathrm{m} / \mathrm{s}$ (positive eastward) for 16 March (a) and 1 July (b) from the HWM-93 model (Hedin et al., 1996), used in simulating the planetary waves.

Figures 4-8 show the latitude-height distributions of $\delta T$ and examples of phase progression for the planetary waves considered. The UFKW propagation results in the strongest perturbations of $T$ in the UMLT region (near the equator), providing $\delta T$ up to $\sim 15 \mathrm{~K}$. Next, in order of magnitude, is the 10-day wave with $\delta T$ reaching $\sim 8 \mathrm{~K}$. The 2 - and 16-day waves can provide $\delta T \sim 5 \mathrm{~K}$ in the UMLT region, while the 5 -day wave gives as little as $\delta T \sim 2 \mathrm{~K}$. 
a)
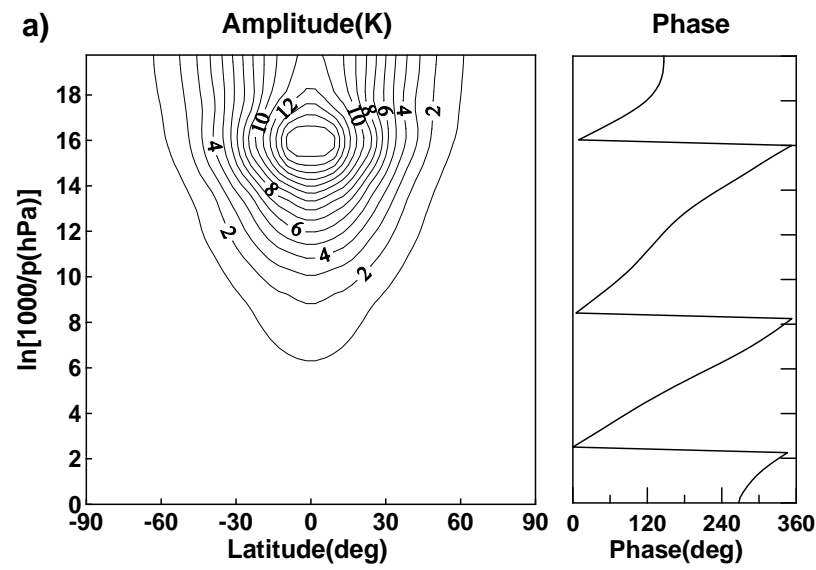

b)
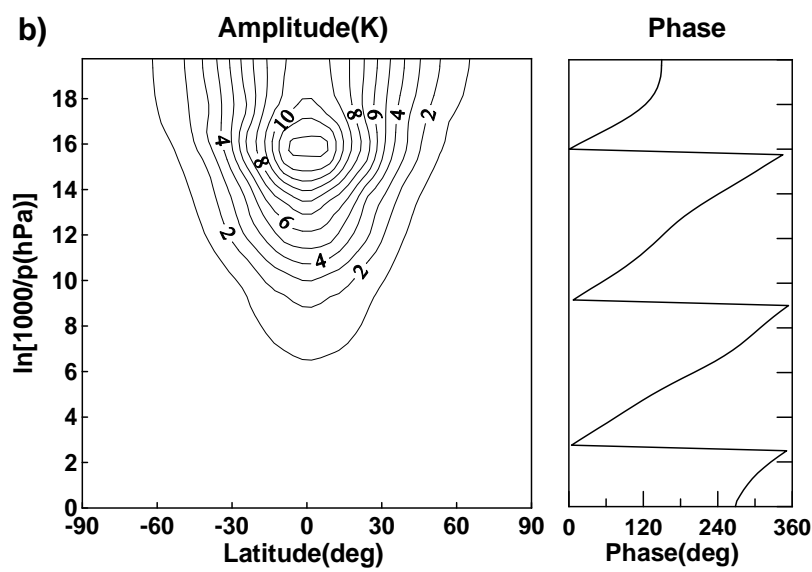

Fig. 4. Latitude-height distribution of amplitude (left) and phase (right) of temperature perturbations for the ultra-fast Kelvin wave for 16 March (a) and 1 July (b). The phases are shown at the equator.

\section{Method for calculating cooling}

To evaluate heat influx in the $\mathrm{CO}_{2} 15-\mu \mathrm{m}$ band, $h_{r}$, in the UMLT region, the non-LTE for vibrational states of $\mathrm{CO}_{2}$ molecules should be taken into account (López-Puertas and Taylor, 2001). The computational code used for evaluating $h_{r}$ is outlined by Ogibalov et al. (2000). The code is based on an optical model presented by Shved et al. (1998). The set of inelastic collisional transitions and their rate constants are also borrowed from Shved et al. (1998). The one exception is for the rate constant for quenching the $\mathrm{CO}_{2}\left(01^{1} 0\right)$ state by $\mathrm{O}$ atoms, which is taken from the recent laboratory measurement of Khvorostovskaya et al. (2002). The profiles of the $\mathrm{O}$ mixing ratio and the only profile of the $\mathrm{CO}_{2}$ mixing ratio are borrowed from the models of Llewellyn and McDade (1996) and Shved et al. (1998), respectively. The latitude-height distributions of climatological temperature, $T_{0}(z, \varphi)$, where $\varphi$ is the latitude, are taken from the MSISE-90 as for the planetary wave models.

To evaluate $h_{r}$, we specify temperature as

$T(z, \varphi, t)=T_{0}(z, \varphi)+\delta T(z, \varphi) \sin [2 \pi t / \tau+\alpha(z, \varphi)]$,
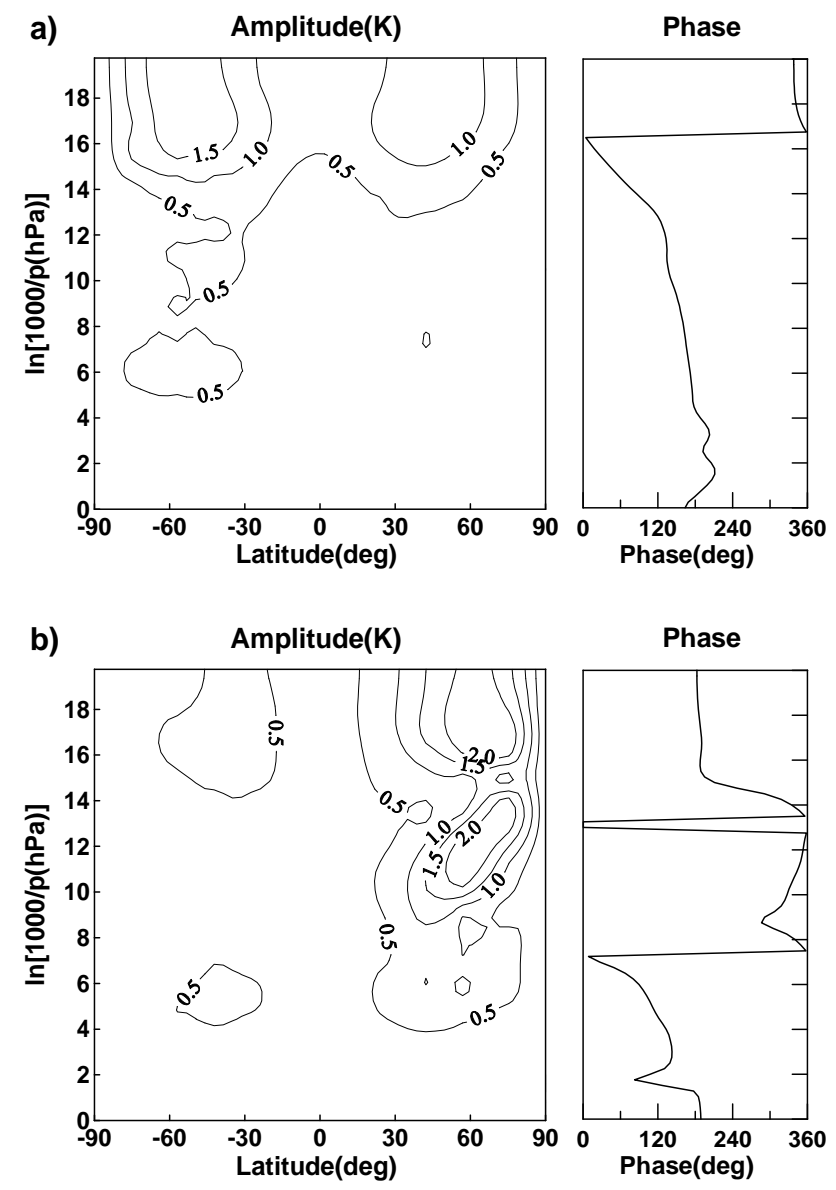

Fig. 5. As in Fig. 4, but for the 5-day wave. The phases are shown at $45^{\circ} \mathrm{S}$ (a) and $45^{\circ} \mathrm{N}(\mathbf{b})$.

where $t$ is the time, $\tau$ and $\alpha$ are the period and phase angle of the wave, respectively. We search for heat influx averaged over $\tau$ :

$\bar{h}_{r}(z, \varphi)=\frac{1}{\tau} \int_{0}^{\tau} h_{r}(z, \varphi, t) d t$.

(Here and below, the over-bar denotes an average over $\tau$.) The calculation of the latitude-height distribution of heat influx for $T_{0}(z, \varphi), h_{r, 0}(z, \varphi)$, makes it possible to find a wavecaused change in the heat influx:

$\Delta h_{r}(z, \varphi)=\bar{h}_{r}(z, \varphi)-h_{r, 0}(z, \varphi)$.

Figure 9 plots $h_{r, 0}(z, \varphi)$ for 16 March and 1 July.

\section{Theory}

In this section we present an explanation for the effect of planetary waves on heat influx in the $\mathrm{CO}_{2} 15-\mu \mathrm{m}$ band. For clarity of explanation we simplify the structure of the band in comparison with its actual structure used in the computational code for evaluating $h_{r}$ (see Sect. 3). Our consideration is restricted to the fundamental transition $00^{0} 0-01^{1} 0$ of the 
a)
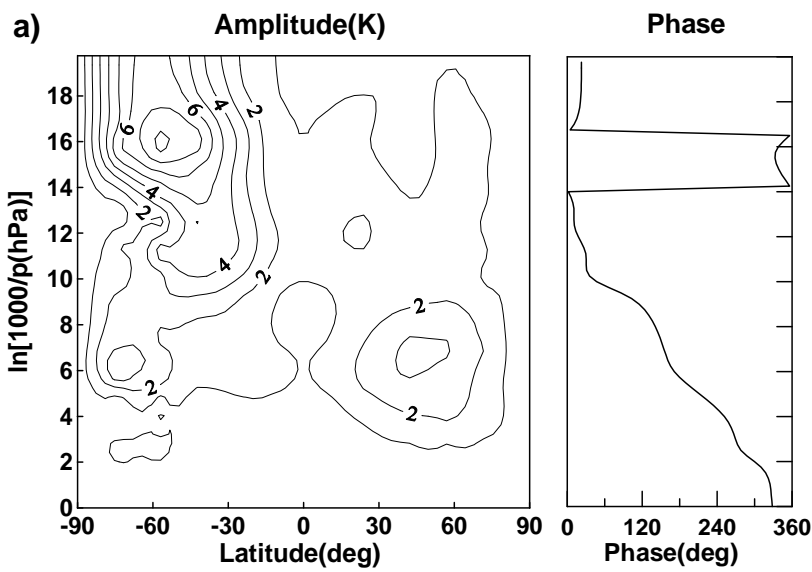

b)
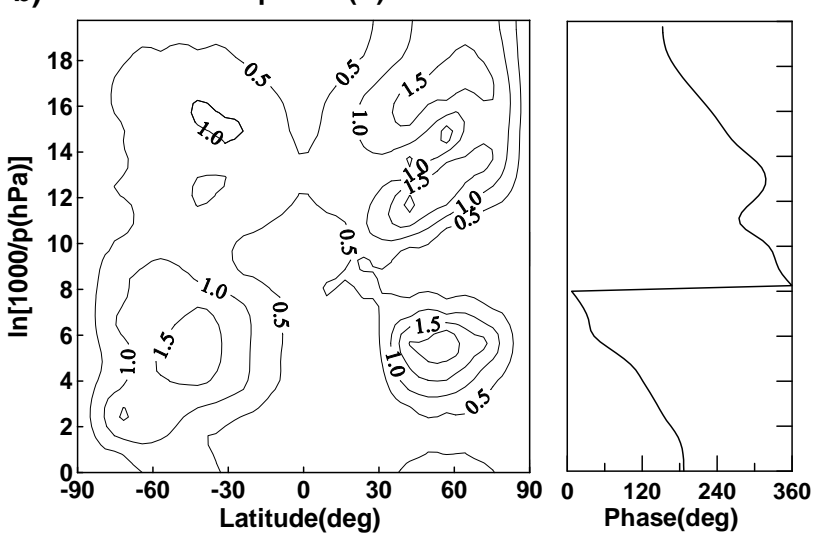

Fig. 6. As in Fig. 4, but for the 10-day wave. The phases are shown at $45^{\circ} \mathrm{N}$ (a) and $45^{\circ} \mathrm{S}(\mathbf{b})$.

main isotop ${ }^{12} \mathrm{C}^{16} \mathrm{O}_{2}$. This transition dominates absolutely in radiative cooling of the lower thermosphere (López-Puertas and Taylor, 2001).

The heat influx in the band is a result of molecular collisions which are accompanied by the transfer of vibrational energy to and from translational energy. Ignoring small disparities in energy of vibrational quanta corresponding different rovibrational transitions of the band, $h_{r}$ per one molecule of air

$h_{r}=h v_{0} c_{C O_{2}}\left(W_{2} C_{21}-W_{1} C_{12}\right)$,

where $h$ is Plank's constant, $v_{0}$ is the frequency of vibrational transition, $c_{M}$ is the volume mixing ratio for the gas constituent $\mathrm{M}$ of the atmosphere, $W_{i}$ is the probability of $\mathrm{CO}_{2}$ molecules (population) to be in the vibrational state $i$, and $C_{i j}$ is the number of vibrational transitions $i \rightarrow j$ in a unit time per one molecule in the initial state $i$. Here, the states $00^{0} 0$ and $01^{1} 0$ are denoted by the subscripts 1 and 2 , respectively. The coefficient $C_{i j}$ is expressed as

$C_{i j}=n \sum_{M} k_{i j, M} c_{M}$,

where $n$ is the total concentration of molecules in the atmosphere, and $k_{i j, M}$ is the rate constant for vibrational transi-

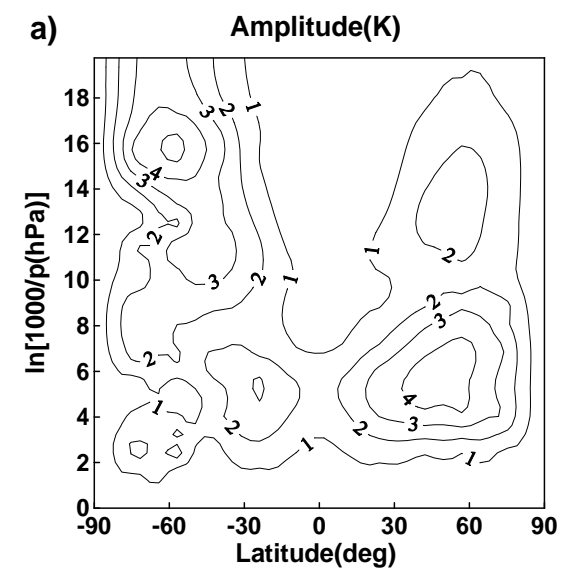

Amplitude (K)

b)
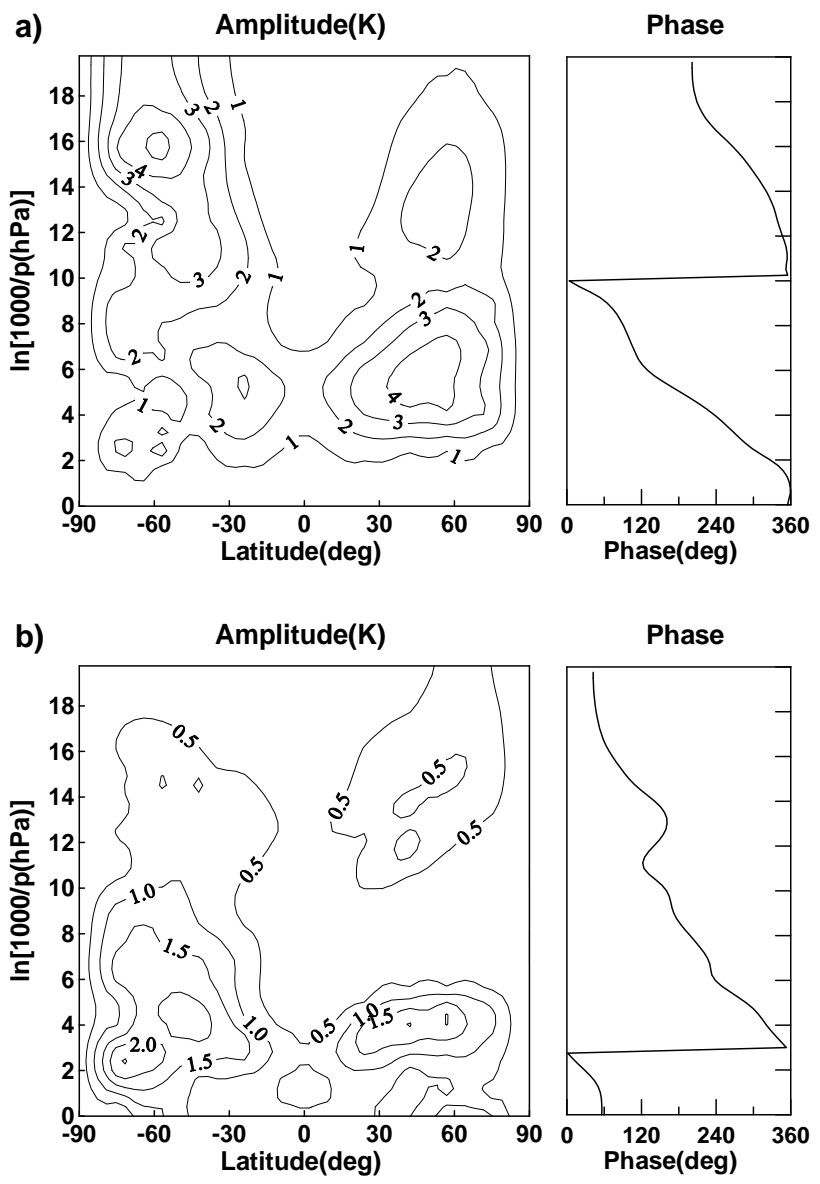

Fig. 7. As in Fig. 4, but for the 16-day wave. The phases are shown at $45^{\circ} \mathrm{N}\left(\right.$ a) and $45^{\circ} \mathrm{S}(\mathbf{b})$.
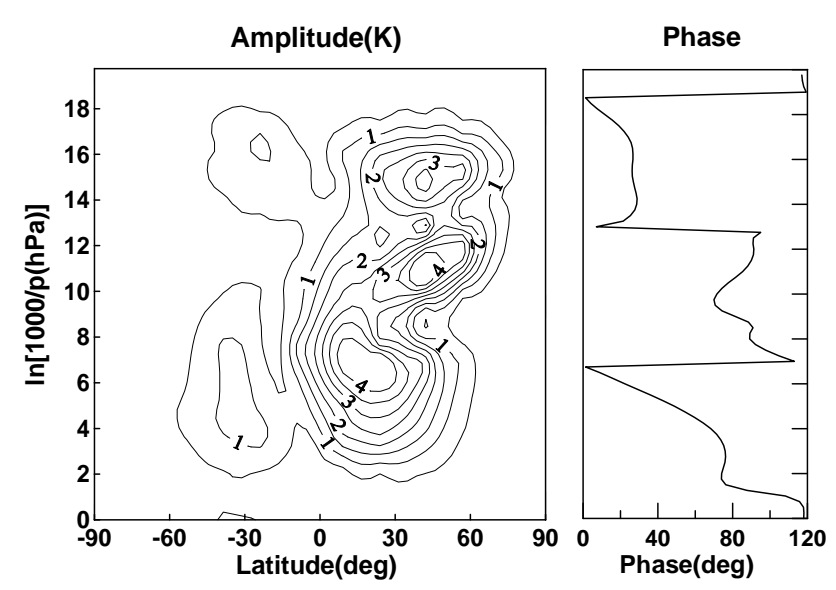

Fig. 8. As in Fig. 4, but for the 2-day wave and only for 1 July. The phase is shown at $45^{\circ} \mathrm{N}$.

tion $i \rightarrow j$ in $\mathrm{CO}_{2}-\mathrm{M}$ collisions. Since the LTE for both translation of air molecules and $\mathrm{CO}_{2}$ rotational states occurs in the UMLT region (López-Puertas and Taylor, 2001), the rate constants $k_{12, \mathrm{M}}$ and $k_{21, \mathrm{M}}$ are related by the detailed balance 
a)

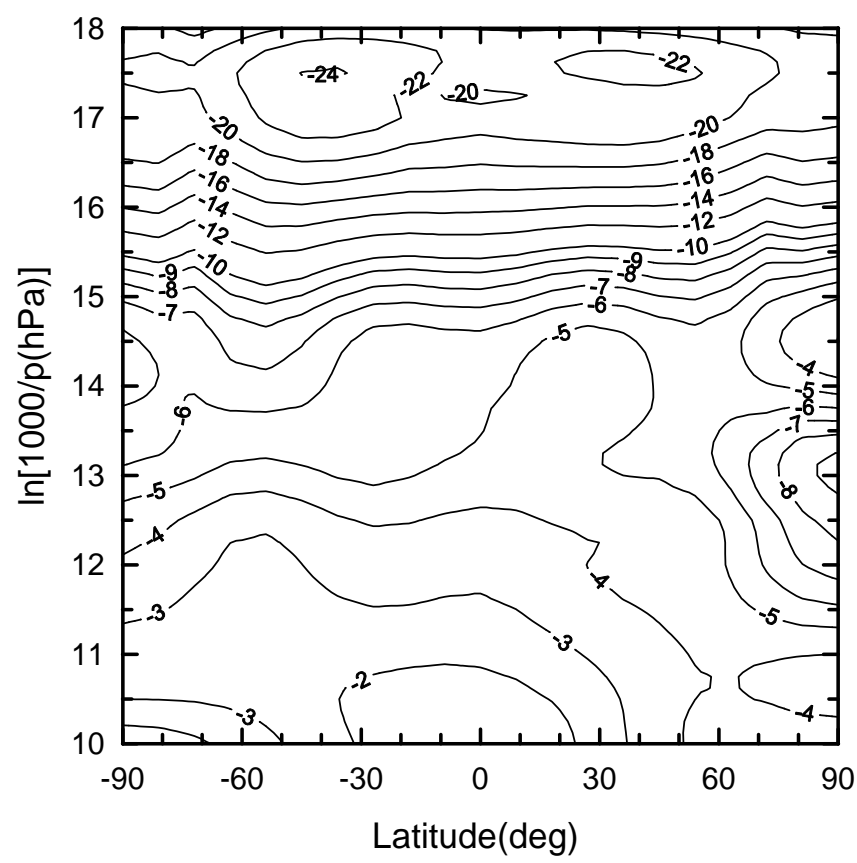

b)

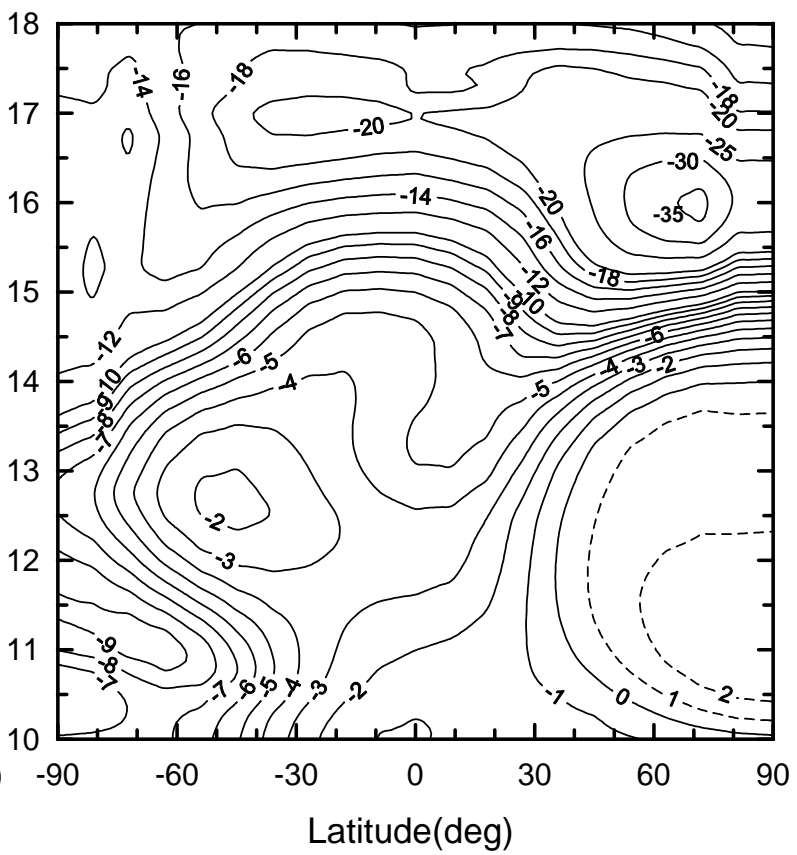

Fig. 9. Latitude-height distributions of heat influx in the $\mathrm{CO}_{2} 15-\mu \mathrm{m}$ band in K/day in the UMLT region for 16 March (a) and 1 July (b), based on vertical profiles of temperature from the MSISE-90 model (Hedin, 1991). The dashed isolines correspond to atmospheric heating.

equation

$g_{1} k_{12, M}=g_{2} k_{21, M} \exp \left(-\frac{h v_{0}}{k T}\right)$,

where $k$ is the Boltzmann constant, and $g_{i}$ is the degeneracy for a state $i$. Here, $g_{1}=1$, and $g_{2}=2$.

The non-LTE for the $\mathrm{CO}_{2} 15-\mu \mathrm{m}$ band occurs above $70 \mathrm{~km}$ (Khvorostovskaya et al., 2002). This means that radiative transitions are involved in the formation of the $01^{1} 0$ state population in the UMLT region, along with collisional transitions. Ignoring a small contribution by the induced photon emission to the state population, $W_{1}$ and $W_{2}$ appear to be related by the equation

$W_{2}\left(A_{21}+C_{21}\right)=W_{1}\left(B_{12} \rho_{r}+C_{12}\right)$,

where $A_{21}$ and $B_{12}$ are the Einstein coefficients of spontaneous photon emission and photon absorption by $\mathrm{CO}_{2}$ molecules, respectively, and $\rho_{r}$ is the "effective" density of photons (see below) for the $00^{0} 0-01^{1} 0$ transitions.

It is appropriate to consider two limiting cases:

A. The LTE case of dominating collisional transitions in the population formation $\left(C_{21} \gg A_{21}, C_{12} \gg B_{12} \rho_{r}\right)$. In this case, in accordance with Eqs. (4), (6), and (7), familiar expressions are valid: Boltzmann's law for state populations,

$\frac{W_{2}}{W_{1}}=\frac{g_{2}}{g_{1}} \exp \left(-\frac{h v_{0}}{k T}\right)$,

and the expression for $h_{r}$,

$h_{r}=h v_{0} c_{C O_{2}} W_{1}\left[B_{12} \rho_{r}-\frac{g_{2}}{g_{1}} A_{21} \exp \left(-\frac{h \nu_{0}}{k T}\right)\right]$.
B. The case of dominating radiative transitions in the population formation $\left(A_{21} \gg C_{21}, B_{12} \rho_{r} \gg C_{12}\right)$. In this case,

$\frac{W_{2}}{W_{1}}=\frac{B_{12} \rho_{r}}{A_{21}}$,

and

$h_{r}=\frac{h v_{0} c_{C O_{2}} W_{1} C_{21}}{A_{21}}\left[B_{12} \rho_{r}-\frac{g_{2}}{g_{1}} A_{21} \exp \left(-\frac{h v_{0}}{k T}\right)\right]$.

It should be noted that the terms which represent the receipts and losses of heat influx, in every limiting case, are proportional to the same expressions $B_{12} \rho_{r}$ and $\left(g_{2} / g_{1}\right) A_{21} \exp$ $\left(-h v_{0} / k T\right)$, respectively. These expressions are combined in the square brackets in Eqs. (9) and (11).

The "effective" density of photons, $\rho_{r}$, is the sum over band lines of the products of the photon's density in a line by its relative strength in the band. The band lines considered differ in both the rotational quantum number $J$ in the lower vibrational state of $00^{0} 0-01^{1} 0$ transition and the belonging to a band branch denoted by the number $\Delta J=J^{\prime}-J$, where $J^{\prime}$ is the rotational quantum number in the upper vibrational state. The P-, Q- and R-branches are numbered sequentially as $\Delta J=-1,0$, and 1. According to Shved et al. (1984), the relative strength of the line is approximated by the product $c_{\Delta J} w_{J}(T)$, where $c_{-1}=c_{1}=1 / 4$ and $c_{0}=1 / 2, w_{J}(T)$ is the Boltzmann probability of finding a linear molecule in the rotational state $J$,

$w_{J}(T)=\frac{h B_{r}}{k T}(2 J+1) \exp \left[-\frac{h B_{r} J(J+1)}{k T}\right]$,

and $B_{r}$ is the rotational constant. 
We use the monochromatic approximation in the radiative transfer theory, since the shape of the line contour is unrelated to the explanation considered. Then, the radiance in photons for a line $(J, \Delta J)$ and a direction of radiative energy flux can be written as

$$
I_{J, \Delta J}=c_{\Delta J} A_{21} \int_{0}^{\infty} d l c_{C O_{2}}(l) n(l) W_{2}(l) w_{J+\Delta J}[T(l)]
$$$$
\exp \left[-c_{\Delta J} B_{12} \int_{0}^{l} d l^{\prime} c_{C O_{2}}\left(l^{\prime}\right) n\left(l^{\prime}\right) W_{1}\left(l^{\prime}\right) w_{J}\left[T\left(l^{\prime}\right)\right]\right],
$$

where $l$ is the length along a ray trajectory from the spatial point considered, and $\rho_{r}$ can be written as

$\rho_{r}=\frac{1}{c} \sum_{J, \Delta J} c_{\Delta J} w_{J}[T(0)] \int_{(4 \pi)} d \omega I_{J, \Delta J}$,

where $c$ is the speed of light, and the integral is taken over the total solid angle.

Since the atmosphere is open to space, the atmospheric infrared emission cools it. However, the infrared emission can also heat in the vicinity of a strong minimum in a vertical profile of $T$, as shown in Fig. 9b. This infrared heating is caused by the following reasons, see Eq. (9) and Eq. (11). The $T$-dependence of heat losses is determined by the exponential function $\exp \left(-h v_{0} / k T\right)$. That is why the heat losses decrease strongly near the $T$ minimum. The heat receipts are proportional to $\rho_{r}$. Those decrease near the $T$ minimum much less, since $\rho_{r}$ is formed by emission from a layer of the atmosphere.

As is seen from Eq. (4), the wave-caused perturbations in $T$ impact on $h_{r}$ via the $T$-dependences of $k_{12, \mathrm{M}}, k_{21, \mathrm{M}}, W_{1}$, and $W_{2}$. However, the $T$ variations of $W_{1}$ are negligible, since the magnitude of $W_{1}$ is little different from 1 at atmospheric temperatures. The quenching of the $01^{1} 0$ state by $\mathrm{O}$ atoms dominates in the thermosphere. That is gradually substituted by quenching during the $\mathrm{CO}_{2}\left(01^{1} 0\right)-\mathrm{N}_{2}$ and $\mathrm{CO}_{2}\left(01^{1} 0\right)-\mathrm{O}_{2}$ collisions with a decrease in $z$. The $T$-dependence of $k_{21, \mathrm{O}}$ is weak (Khvorostovskaya et al., 2002). However, those of $k_{21, \mathrm{~N}_{2}}$ and $k_{21, \mathrm{O}_{2}}$ are tangible (e.g. Shved et al., 1998), though they are much weaker than the $T$-dependence represented by the factor $\exp \left(-h v_{0} / k T\right)$. Hence, in accordance with Eq. (6), this factor governs mainly the $T$-dependence of $k_{21, \mathrm{M}}$. From Eqs. (7) and (12)-(14), the $T$-dependence of $W_{2}$ is very complicated. First, the $T$-dependences of the rate constants $k_{21, \mathrm{M}}$, factor $\exp \left(-h v_{0} / k T\right)$, and function $w_{J}(T)$ contribute to it. Second, $W_{2}$ is determined via $\rho_{r}$ by $T$ in a layer of the atmosphere.

Since the factor $\exp \left(-h v_{0} / k T\right)$ is nonlinear in $T$, its averaging over $\tau$ results in

$\overline{\exp \left(-h v_{0} / k T\right)}>\exp \left(-h v_{0} / k T_{0}\right)$ at atmospheric temperatures considered, if $T$ in Eq. (15) is given by Eq. (1) with $\delta T \ll T_{0}$. That is why the wave-caused perturbations lead universally to an increase in heat losses.

As is seen from Eqs. (9) and (11), the wave-caused perturbations in heat receipts are determined by $\rho_{r}$ averaged over $\tau$,

$\overline{\rho_{r}}=\frac{1}{c} \sum_{J, \Delta J} c_{\Delta J} \overline{\left(w_{J}[T(0)] \int_{(4 \pi)} d \omega I_{J, \Delta J}\right)}$.

From Eq. (16), the wave impacts on the population of rotational states and the photon density in lines in spatial point considered. However, the photon density, in accordance with Eq. (13), is the resultant effect of the wave on a layer of the atmosphere that makes the analysis of the wave impact on heat receipts difficult. Two inferences about wave effects on heat receipts can yet be made. First of all, due to a smoothing effect of integrating in Eq. (13) along a ray trajectory, the stronger that the phase of the wave varies with $z$, the weaker the wave-caused perturbations are in $I_{J, \Delta J}$. Secondly, one can understand the way in which the wave-caused local perturbation in the rotational state populations acts on heat receipts. As is seen from Eq. (12), an increase in $T$ results in a nonlinear rise of the probabilities $w_{J}$ for large numbers $J$ at the decrease of ones for small numbers $J$. This leads to enhancing of the radiation absorption in weak lines (large $J$ ) and to attenuating that in strong lines (small $J$ ). From Eq. (13), the weaker the line, the farther from the height level under consideration the radiation absorbed is formed. Since the optical depth of the thermosphere in the lines of the $\mathrm{CO}_{2}$ $15-\mu \mathrm{m}$ band is less than one, the UMLT photon density in the band is mainly formed by the upward radiation. The rise of $T$ down from the mesopause results in an associated increase in the relative population of $01^{1} 0$ state, $W_{2} / W_{1}$ (Ogibalov et al., 1998; López-Puertas and Taylor, 2001). Thus, the weaker a line, the more $W_{2} / W_{1}$ in the layer forming upward radiation. So, it is due to weak lines that the wave-caused perturbations lead to an increase in radiation absorption in the band at the height level under consideration and correspondingly to the rise in the UMLT heat receipts averaged over $\tau$.

For the sake of discussion in Sect. 5, the following should be noted. As indicated above, there are two features in the lower thermosphere. First, the photon density in the $\mathrm{CO}_{2}$ $15-\mu \mathrm{m}$ band is virtually constant, as formed by the emission of the underlaying atmosphere. Second, the coefficient $C_{21}$ depends on $T$ slightly. From Eqs. (11) and (14), the $T$-dependence of heat receipts in the lower thermosphere is therefore governed by $w_{J}(T)$.

\section{Results and discussion}

Figures 10-14 plot the UMLT distributions $\Delta h_{r}(z, \varphi)$ from Eq. (3) for the planetary waves considered.

Similar to the estimations of Fomichev et al. (1986) for tides and internal gravity waves, the principal effect of planetary waves on radiative heat influx is an increase in the 
a)

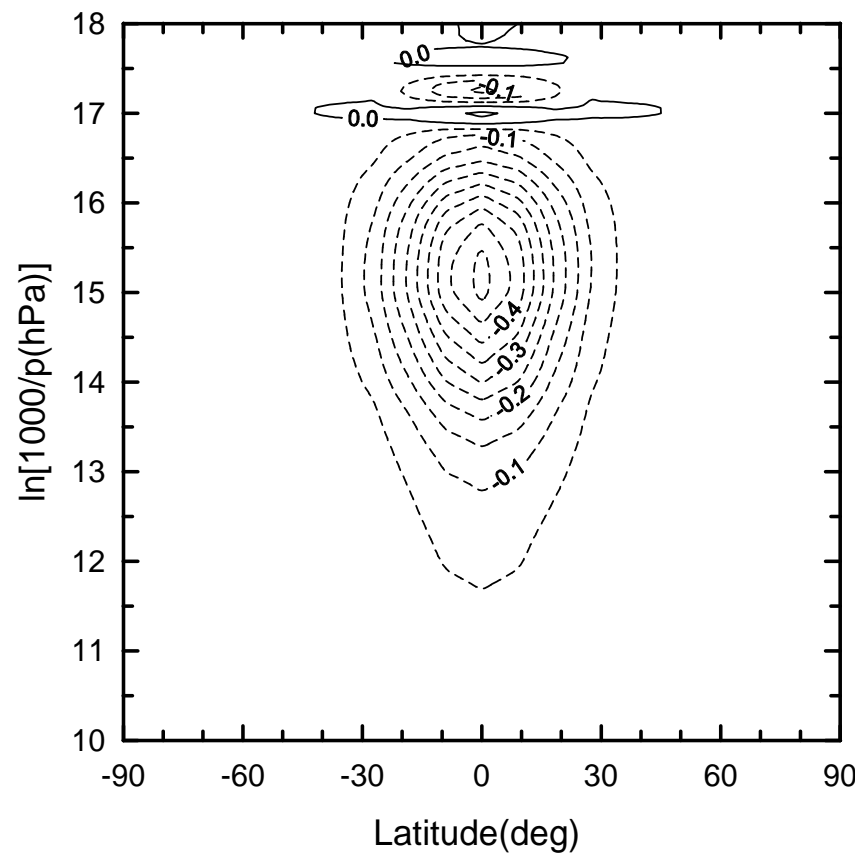

b)

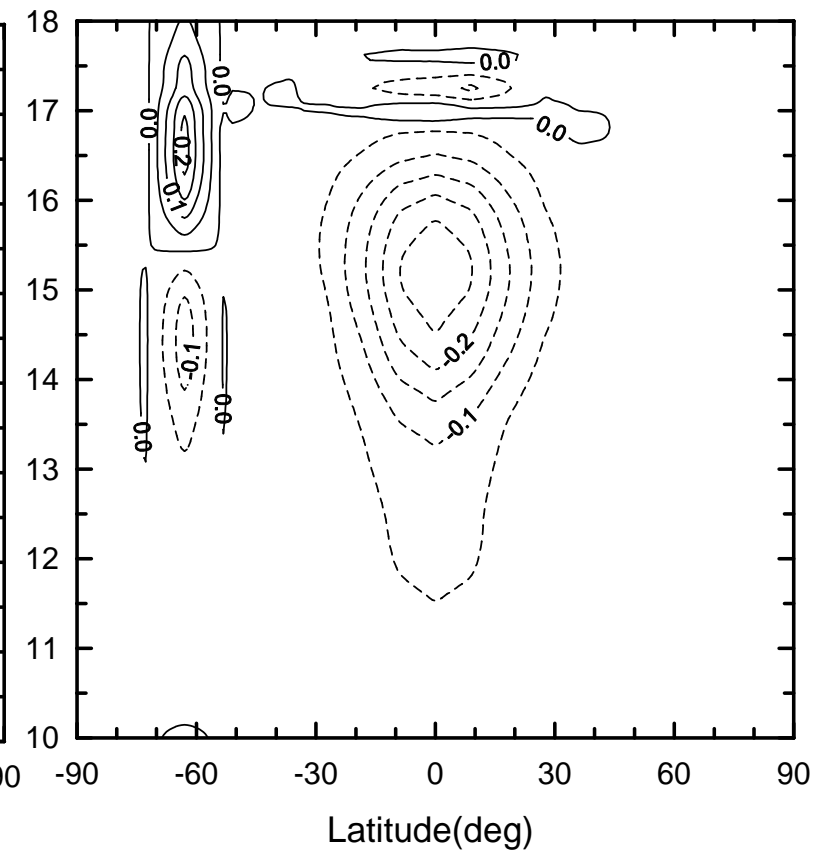

Fig. 10. Latitude-height distributions of change in heat influx in $\mathrm{K} /$ day due to perturbations of the $\mathrm{CO}_{2} 15-\mu \mathrm{m}$ emission during propagation of the ultra-fast Kelvin wave for 16 March (a) and 1 July (b). The dashed isolines correspond to increasing the cooling rate.

a)

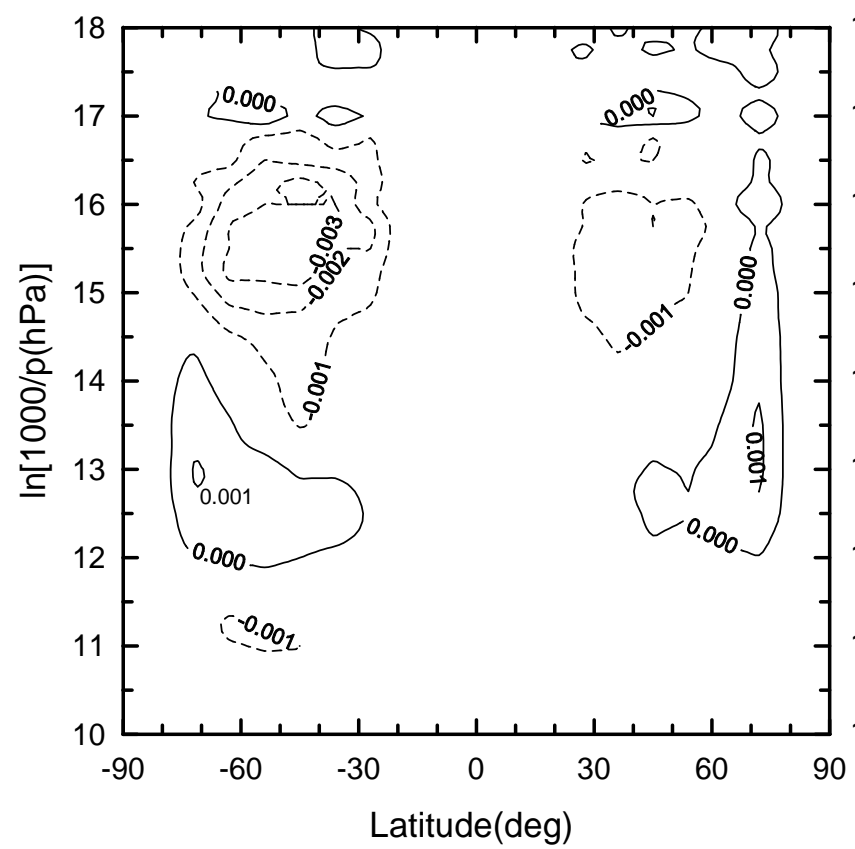

b)

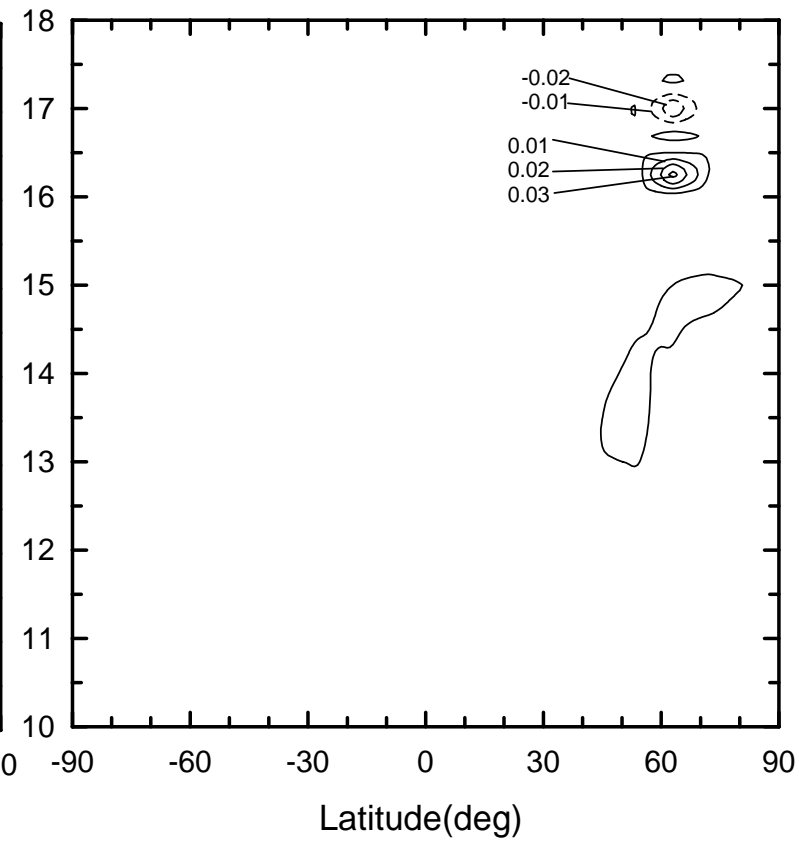

Fig. 11. As in Fig. 10, but for the 5-day wave.

cooling $\left(\Delta h_{r}<0\right)$. Also similar to those estimations, the $\varphi$-dependence of $\Delta h_{r}$ reflects roughly that of $\delta T$ (Figs. 4$8)$. Namely, the larger $\delta T$ corresponds to the stronger cooling rate. The profiles $\delta T(z)$ of the 2-, 5-, 10-, and 16-day waves in the UMLT region (Figs. 5-8) show maximums in the upper mesosphere and lower thermosphere. Those result in maximums in the cooling rate in the $95-105 \mathrm{~km}$ layer of the thermosphere and near $75 \mathrm{~km}$ in the mesosphere. The $\delta T$-profiles of UFKW (Fig. 4) are characterized by the only thermospheric maximum, giving correspondingly that in the cooling rate. 
Table 1. Maximum order-of-magnitude of incrasing the $\mathrm{CO}_{2} 15-\mu \mathrm{m}$ band cooling rate in the upper mesosphere and lower thermosphere due to the temperature perturbations caused by a planetary wave.

\begin{tabular}{lrll}
\hline $\begin{array}{l}\text { Planetary } \\
\text { wave (date) }\end{array}$ & $\begin{array}{r}\text { Characteristic } \\
\text { height }(\mathrm{km}) \text { and } \\
\text { latitude of }\end{array}$ & $\begin{array}{l}\text { Cooling rate } \\
\text { in K/day }\end{array}$ & $\begin{array}{l}\text { Cooling rate in } \\
\text { Kelvin per } \\
\text { wave period }\end{array}$ \\
$\begin{array}{r}\text { maximum increase } \\
\text { in cooling rate }\end{array}$ & \\
\hline Ultra-fast & 100, equator & 0.5 & 3 \\
Kelvin wave & & & \\
(16 March) & $75, \quad 40^{\circ} \mathrm{N}$ & 0.02 & 0.5 \\
2-day wave & $100, \quad 40^{\circ} \mathrm{N}$ & 0.03 & 0.5 \\
(1 July) & $75, \quad 60^{\circ} \mathrm{S}$ & 0.001 & 0.005 \\
5-day wave & $100, \quad 50^{\circ} \mathrm{S}$ & 0.003 & 0.015 \\
(16 March) & $75, \quad 50^{\circ} \mathrm{S}$ & 0.05 & 0.5 \\
10-day wave & $100, \quad 50^{\circ} \mathrm{S}$ & 0.1 & 1 \\
(16 March) & $75, \quad 50^{\circ} \mathrm{S}$ & 0.03 & 0.5 \\
16 day-wave & $100, \quad 60^{\circ} \mathrm{S}$ & 0.05 & 1 \\
(16 March) & & & \\
\hline
\end{tabular}

a)

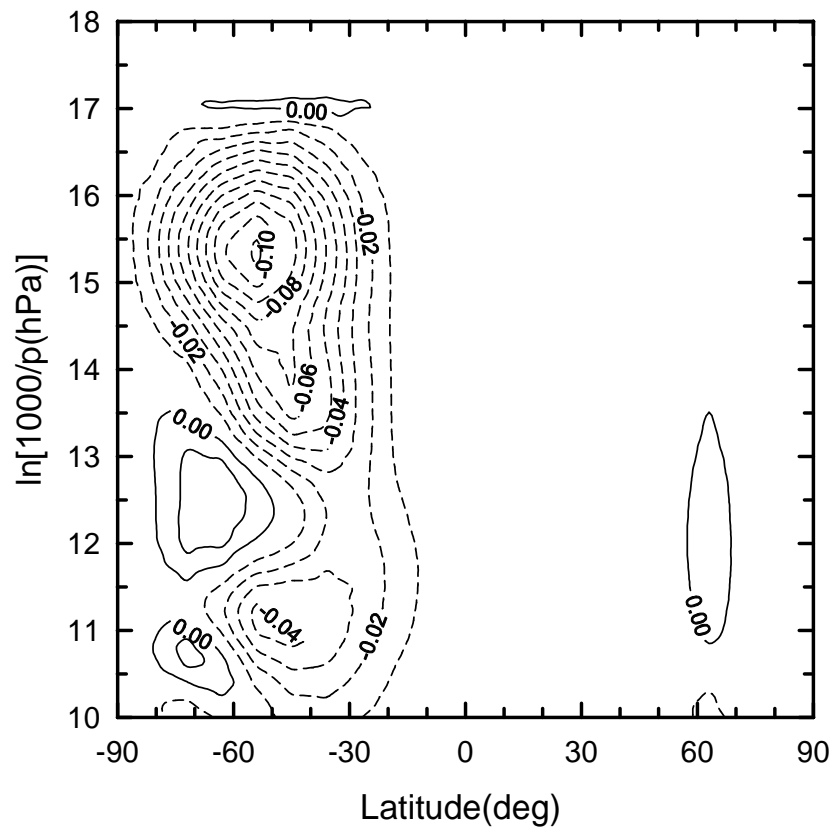

b)

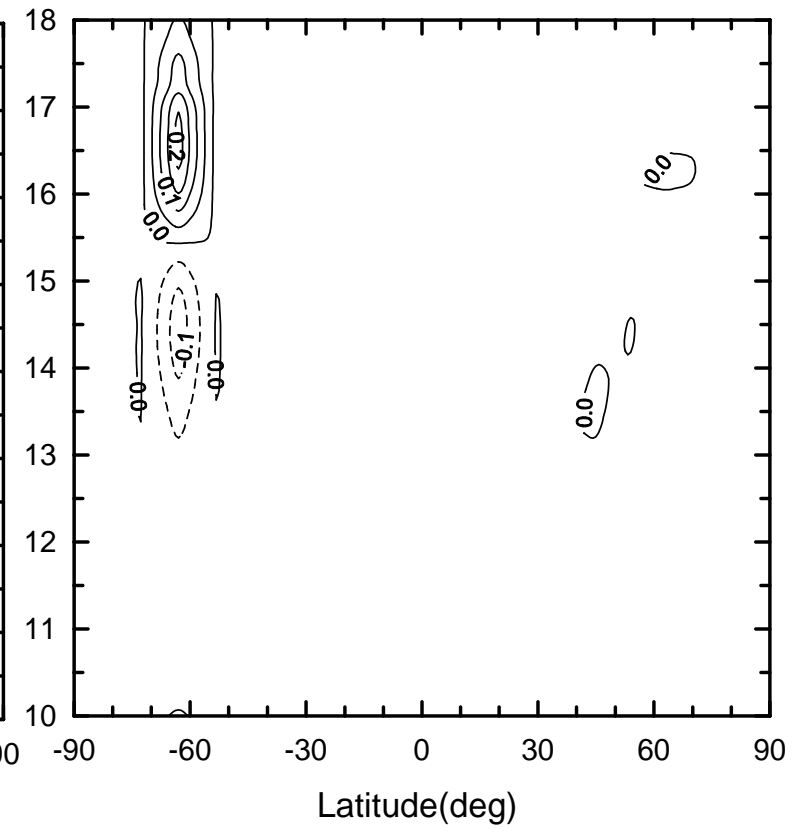

Fig. 12. As in Fig. 10, but for the 10-day wave.

The maximum orders of both the rate of additional radiative cooling due to planetary waves and this cooling per wave period are shown in Table 1 . Comparing the rate of the indicated "wave" cooling (Figs. 10-14) with the radiative cooling rate in the atmosphere, unperturbed by waves (Fig. 10), it is possible to conclude that the UFKW contributes maximally to all the waves to a cooling rate up to $\sim 0.1$ of the cooling rate unperturbed. In the lower thermosphere the other waves each contribute no more than $\sim 0.01$ of that. The latter assertion is even concerned with the 10-day wave with the thermo- spheric maximum in $\delta T(z)$ which is less than that of UFKW by a factor of $\sim 2$ only. Since the thermospheric maximums in $\delta T(z)$ for the UFKW and 10-day wave, located virtually at the same height, are strongly distinct in latitude, the case considered shows the strong dependence of the "wave" cooling rate on the $T_{0}$-profile features (Fig. 2). In the upper mesosphere the relative increase in the cooling rate due to any one of the 2-, 5-, 10-, and 16-day waves is more than that in the lower thermosphere up to $\sim 0.02$ for the 10 -day wave. 
a)

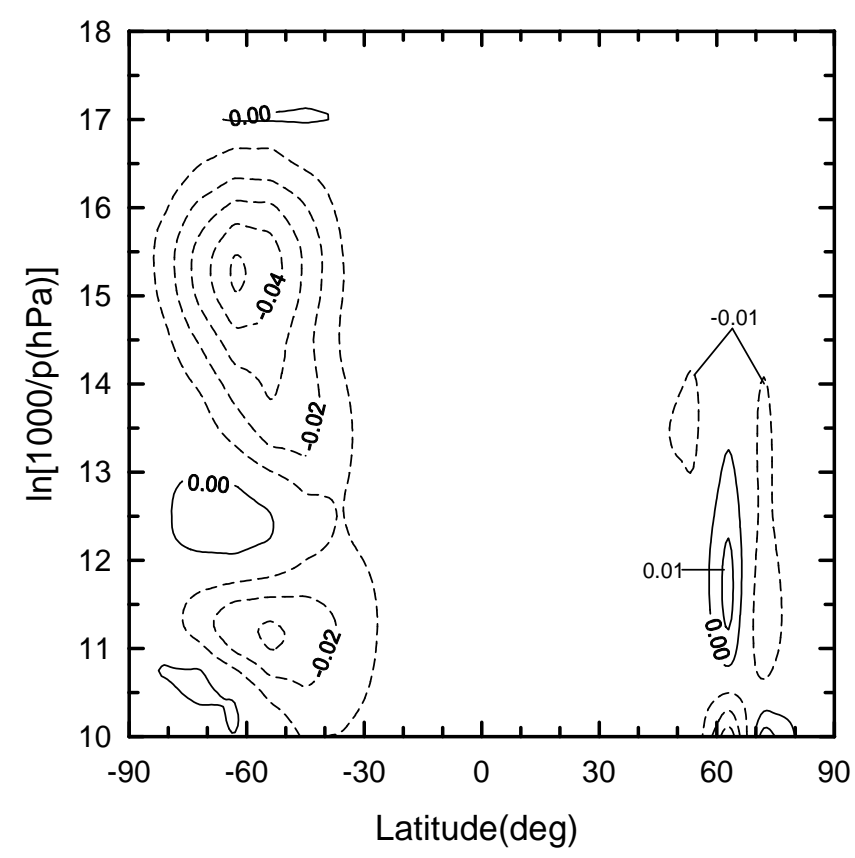

b)

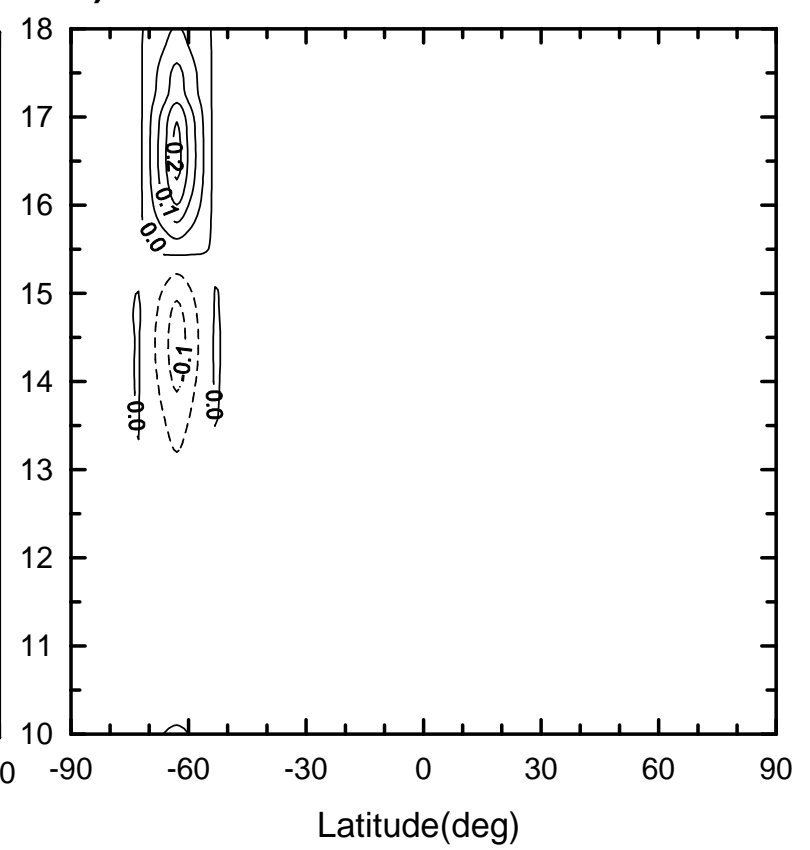

Fig. 13. As in Fig. 10, but for the 16-day wave.

Our estimates of $\Delta h_{r}$ show that only the UFKW can tangibly contribute to the radiative cooling of the UMLT region. The contribution of any one of the 2-, 10-, and 16-day waves does not exceed an error in estimating the radiative heat influx, which is certainly no less than $1 \%$. The contribution of the 5-day wave is negligible at all.

There are $T_{0}$-profiles at which heat receipts and losses compensate in fact for each other near the mesopause (see, for example, Fig. 9b), resulting in $\left|\Delta h_{r}\right| \geq\left|h_{r}, 0\right|$. At these conditions the solar radiative heating is balanced by the advection of cold and/or adiabatic cooling (Fomichev et al., 2002). The additional radiative cooling due to 2-, 5-, 10, and 16-day waves is negligible in relation to the dynamic cooling indicated.

As is seen from Figs. 10-14, there are areas of additional heating in the $\mathrm{CO}_{2} 15-\mu \mathrm{m}$ band due to planetary waves $\left(\Delta h_{r}>0\right)$. However, these areas are either relatively small in volume or characterized by very small rates of heating. The "wave" heating is mainly caused by the effect of weak lines, described in Sect. 4. Their effect depends on the features of the profiles of $T_{0}(z)$ and $\delta T(z)$. Three cases of "wave" heating are to be discussed:

1. For the 2-day wave, there is an area of heating in the upper mesosphere, centered at about $45^{\circ} \mathrm{N}$ and logpressure height $x=13$ (Fig. 14). This area is configured as the area of reduced $\delta T$ in Fig. 8. The $\delta T$ rise up and down from the latter area results in a sharp increase in the heat losses' term in the $h_{r}$ expression. The sign of $\Delta h_{r}$ is correspondingly reversed. The case considered shows clearly that $\Delta h_{r}>0$ can be realized only for relatively little magnitudes of $\delta T$.
2. The UFKW, 10-, and 16-day waves for 1 July and $50^{\circ} \mathrm{S}-70^{\circ} \mathrm{S}$ result in the areas of "wave" heating, which are closely configured and located in the lower thermosphere between $x \approx 15.5$ and $x \approx 18$ (Figs. 10b, 12b, and 13b). These areas coincide with the area in Fig. 9b, in which heat influx varies slightly in spite of the fact that $T_{0}$ increases by a factor of $\sim 2$ in the $x$ range indicated. In this case the thermospheric photon density in the $\mathrm{CO}_{2} 15-\mu \mathrm{m}$ band (see also the latter paragraph of Sect. 4) is such that a variation in thermospheric $T$, producing proper variations in $w_{J}(T)$ and $\exp \left(-h v_{0} / k T\right)$, does virtually not change the heat influx. The peculiarity in the photon density is caused by features in the $T_{0^{-}}$ profile below $x=15$. The most prominent feature in the $T_{0}$-profiles under consideration is, in accordance with MSISE-90, a weak variation of $T_{0}$ with height in the range of $x \approx 13-15$ (Fig. 2b). The case discussed is another example of the action of the $T_{0}$-profile on $\Delta h_{r}$. This effect is not detected from the 2- and 5-day waves because their $\delta T$ are much weaker in the area considered.

3. The heating in a small area of the lower thermosphere near $x=16$ for 1 July and $\sim 60^{\circ} \mathrm{N}$ due to the 2 - and 5-day waves (Figs. 11b and 14b) also results from features of the $T_{0}$-profile (Fig. 2b). This area coincides with the area of the maximum rate of radiative cooling in the lower thermosphere (Fig. 9b). The maximum is caused by the very cold mesopause at high latitudes in summer. 


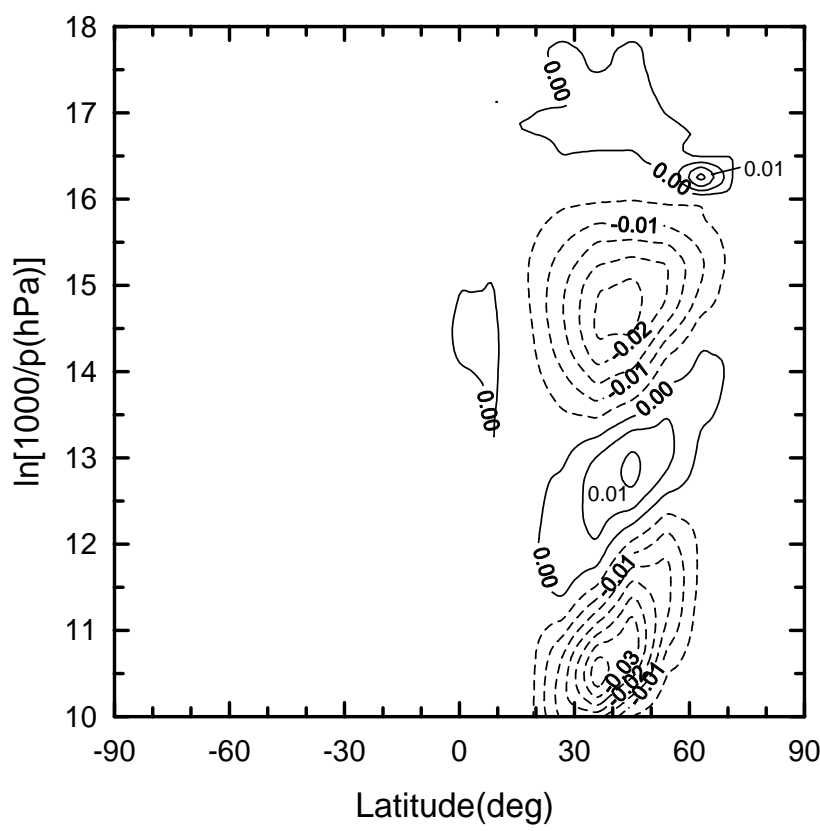

Fig. 14. As in Fig. 10, but for the 2-day wave and only for 1 July.

The distributions $\Delta h_{r}(z, \varphi)$ represented only take into account the $T$-variation in the wave. This variation influences the radiative heat influx through the $T$-factor $\exp \left(-h v_{0} / k T\right)$ of detailed balance Eq. (6), Boltzmann's law Eq. (12) for the rotational state populations, the $T$-dependence of the rate constants for vibration-translation energy exchange in molecular collisions, and the $T$-dependence of the line shape. However, the propagation of the wave is also accompanied by the variation of air density. This variation results in an $n$-variation with $\delta n / n_{0} \sim \delta T / T_{0}$, where $\delta n$ is the amplitude of change in $n$ in the planetary wave, and $n_{0}$ is the background concentration of the air molecules. Similar to the $T$-variation, the $n$-variation acts on $h_{r}$ via the coefficients $C_{i j}$, see Eqs. (4) and (5) both explicitly and implicitly. In the latter case the $n$-variations in a layer of the atmosphere are involved through the quantity $W_{2}$, and the dependence of $h_{r}$ on those is very complicated, as is seen from Eqs. (7), (13), and (14).

It may be safe to suggest for general reasons that the wave $n$-variation contributes little to $\Delta h_{r}$ as compared with the wave $T$-variation. That results from the linear dependence of $C_{i j}$ on $n$, whereas the influence of the $T$-variation is realized through nonlinear functions of $T$. As was shown in our evaluations by the example of the $T$-variation impact, the principal influence of the wave perturbations is realized via the factors $C_{i j}$ in Eq. (4). However, if the averaging over $\tau$ of the main $T$-dependence in $C_{12}$, specified by the factor $\exp \left(-h v_{0} / k T\right)$, results in a tangible departure from $\exp \left(-h v_{0} / k T_{0}\right)$, the averaging of $n$ gives $n_{0}$. As to the influence of wave perturbations on $\Delta h_{r}$ via $W_{2}$ in Eq. (4), it is weak even for the $T$-variation. For the $n$-variation it is expected to be weaker.
It is seen from Eq. (13) that the rigorous consideration of $n$-variation effect complicates the code for radiative transfer calculation. However, the complicating of the computational code is unlikely to be justified due to the small impact expected.

\section{Conclusions}

1. According to the steady-state 2-D linearized model of global-scale waves, the maximum order of the wave amplitude of temperature in the UMLT region is equal to $15 \mathrm{~K}$ for UFKW, $8 \mathrm{~K}$ for the 10 -day wave, $5 \mathrm{~K}$ for the 2 - and 16-day waves, and $2 \mathrm{~K}$ for the 5-day wave.

2. The wave-caused variation in heat influx in the $\mathrm{CO}_{2} 15-$ $\mu \mathrm{m}$ band, averaged over the wave period, depends on both the amplitude of temperature and the temperature profile in the atmosphere unperturbed by the wave. Although this variation can be of any sign, an additional increase in radiative cooling is the prevailing effect of the planetary wave in the UMLT region. The UFKW results in an increasing of the cooling rate in the lower thermosphere up to $\sim 0.1$ of the cooling rate in unperturbed atmosphere. The tangible contributions of the 2-, 10-, and 16-day waves are questionable, since their "wave" heat influxes, in accordance with our consideration, do not exceed an error in estimating the radiative heat influx. The contribution of the 5-day wave is negligible at all.

Acknowledgements. Our work was supported by the Russian Foundation for Basic Research under grant 03-05-64700 and Russian Ministry for Education under grant E02-8.0-42. V.P. Ogibalov was also partly supported by the Deutscher Akademischer Austauschdienst (DAAD) under grant A-03-06056 and the Wenner-Gren Foundation (Sweden).

Topical Editor U.-P. Hoppe thanks a referee for his help in evaluating this paper.

\section{References}

Ahlquist, J. E.: Climatology of normal mode Rossby waves, J. Atmos. Sci., 42, 2059-2068, 1985.

Andrews, D. G., Holton, J. R., and Leovy, C. B.: Middle atmosphere dynamics, Academic Press, Orlando, Florida, 1987.

Canziani, P. O., Holton, J. R., Fishbein, E., Froidevaux, L., and Waters, J. W.: Equatorial Kelvin waves: A UARS MLS view, J. Atmos. Sci., 51, 3053-3076, 1994.

Dickinson, R. E.: Infrared radiative cooling in the mesosphere and lower thermosphere, J. Atmos. Terr. Phys., 46, 995-1008, 1984.

Fedulina, I. N., Pogoreltsev, A. I., and Vaughan, G.: Seasonal, interannual and short-term variability of planetary waves in Met Office assimilated fields, Q. J. Roy. Meteorol. Soc., in press, 2004.

Fomichev, V. I., Shved, G. M., and Kutepov, A. A.: Radiative cooling of the $30-110 \mathrm{~km}$ atmospheric layer, J. Atmos. Terr. Phys. 48, 529-544, 1986.

Fomichev, V. I., Ward, W. E., Beagley, S. R., McLandress, C., McConnell, J. C., McFarlane, N. A., and Shepherd, T. G.: Extended Canadian Middle Atmosphere Model: zonal-mean climatology and physical parameterizations, J. Geophys. Res., 107(D10), doi: 10.1029/2001JD000479, 2002. 
Fritts, D. C., Isler, J. R., Lieberman, R. S., Burrage, M. D., Marsh, D. R., Nakamura, T., Tsuda, T., Vincent, R. A., and Reid, I. M.: Two-day wave structure and mean flow interactions observed by radar and High Resolution Doppler Imager, J. Geophys. Res. (Sect. D), 104, 3953-3969, 1999.

Hedin, A. E.: Extension of the MSIS thermosphere model into the middle and lower atmosphere, J. Geophys. Res., A96, 11591172, 1991.

Hedin, A. E., Fleming, E. L., Manson, A. H., Schmidlin, F. G., Avery, S. K., Clark, R. R., Franke, S. J., Franser, G. J., Tsuda, T., Vial, F., and Vincent, R. A.: Empirical wind model for the upper, middle and lower atmosphere, J. Atmos. Terr. Phys., 58, 1421-1447, 1996.

Khvorostovskaya, L. E., Potekhin, I. Yu., Shved, G. M., Ogibalov, V. P., and Uzyukova, T. V.: Measurement of the rate constant for quenching $\mathrm{CO}_{2}\left(01^{1} 0\right)$ by atomic oxygen at low temperatures: reassessment of the rate of cooling by the $\mathrm{CO}_{2} 15-\mu \mathrm{m}$ emission in the lower thermosphere, Izvestiya, Atmos. Ocean. Phys., Engl. Transl., 38, 613-624, 2002.

Kutepov, A. A. and Shved, G. M.: Radiative transfer in the $15 \mu \mathrm{m}$ $\mathrm{CO}_{2}$ band with the breakdown of local thermodynamic equilibrium in the Earth's atmosphere, Atmos. Ocean. Phys., 14, 18-30, 1978.

Llewellyn, E. J. and McDade, I. C.: A reference model for atomic oxygen in the terrestrial atmosphere, Adv. Space Res., 18(9/10), 209-226, 1996.

Lindzen, R. S., Straus, D. M., and Katz, B.: An observational study of large-scale atmospheric Rossby waves during FGGE, J. Atmos. Sci., 41, 1320-1335, 1984.

López-Puertas, M. and Taylor, F. W.: Non-LTE radiative transfer in the atmosphere, Word Scientific, Singapore, 2001.

Ogibalov, V. P., Kutepov, A. A., and Shved, G. M.: Non-local thermodynamic equilibrium in $\mathrm{CO}_{2}$ in the middle atmosphere. II. Populations in the $v_{1} v_{2}$ mode manifold states, J. Atmos. SolarTerr. Phys., 60, 315-329, 1998.
Ogibalov, V. P., Fomichev, V. I., and Kutepov, A. A.: Radiative heating effected by infrared $\mathrm{CO}_{2}$ bands in the middle and upper atmosphere, Izvestiya, Atmos. Ocean. Phys., Engl. Transl., 36, 454-464, 2000.

Pogoreltsev, A. I.: Simulation of the influence of stationary planetary waves on the zonally averaged circulation of the mesosphere/lower thermosphere region, J. Atmos. Terr. Phys., 58, 901-909, 1996.

Pogoreltsev, A. I.: Simulation of planetary waves and their influence on the zonally averaged circulation in the middle atmosphere, Earth, Planets and Space, 51, 773-784, 1999.

Pogoreltsev, A. I.: Numerical simulation of secondary planetary waves arising from the nonlinear interaction of the normal atmospheric modes, Phys. Chem. Earth (Part C), 26, 395-403, 2001.

Roble, R. G.: Energetics of the mesosphere and thermosphere, in: The upper mesosphere and lower thermosphere: A review of experiment and theory, (Ed) Johnson, R. M., and Killen, T. L., Geophysical Monograph 87, 1-21, 1995.

Shved, G. M., Ishov, A. G., and Kutepov, A. A.: Universal functions for estimating total vibration-rotation band absorptance? I. Linear molecules and spherical tops, J. Quant. Spectrosc. Radiat. Transfer, 31, 35-46, 1984.

Shved, G. M., Kutepov, A. A., and Ogibalov, V. P.: Non-local thermodynamic equilibrium in $\mathrm{CO}_{2}$ in the middle atmosphere. I. Input data and populations of the $v_{3}$ mode manifold states, J. Atmos. Solar-Terr. Phys., 60, 289-314, 1998.

Smith, A. K., Preusse, P., and Oberheide, J.: Middle atmosphere Kelvin waves observed in Cryogenic Infrared Spectrometers and Telescopes for the Atmosphere (CRISTA) 1 and 2 temperature and trace species, J. Geophys. Res., 107(D23), 8177, doi: 10.1029/2001JD000577, 2002.

Thayaparan T., Hocking, W. K., and MacDouglall, J.: Amplitude, phase, and period variations of the 2-day wave in the mesosphere and lower thermosphere over London, Canada (43 N, $81 \mathrm{~W}$ ), during 1993 and 1994, J. Geophys. Res. (Sect. D), 102, 9461-9478, 1997. 